\title{
Retrospective analysis of infections prevalence in patients with progressive systemic sclerosis treated with cyclophosphamide
}

\author{
Małgorzata Schlabs' ${ }^{1,2}$ Katarzyna Pawlak-Buś1, ${ }^{1}$, Piotr Leszczyński ${ }^{1,2}$ \\ ${ }^{1}$ Department of Rheumatology and Osteoporosis, Jozef Strus Municipal Hospital in Poznan, Poland \\ ${ }^{2}$ Department of Rheumatology and Rehabilitation, Poznan University of Medical Sciences, Poland
}

\begin{abstract}
Aim. Assessment of infections prevalence rate, type and severity in patients diagnosed with progressive systemic sclerosis (PSS), treated with cyclophosphamide (CTX), during 12 months of observations.

Material and methods. A retrospective analysis of mild, moderate and severe infections in 17 women with a mean age of $58.8 \pm 10.0$, based on an interview, physical examination, additional tests, and available medical records.

Results. 46 various infections were diagnosed in the analysed group of patients. 32 (69.6\%) infections involved the respiratory system, and $14(30.4 \%)$ infections concerned the urinary tract. The average frequency per one patient was $2.7 \pm 3.5$ (median: 2) events during 12 months of observations. The majority of infections, $60.9 \%$ $(n=28)$, were mild ones of slight intensity, and $37.0 \%(n=17)$ were moderate ones. Only one person $(2.2 \%$ of all infections) had a severe infection requiring hospitalisation.

Conclusions. In the studied group the infection prevalence rate was comparable to that in a healthy population. The majority of infections were mild and involved the respiratory system. Basis of conducted analysis 12 months intravenous administration of CTX is not a factor significantly increasing a risk of severe infections in the studied group of patients. In PSS patients CTX pulse therapy is relatively safe, as it does not cause severe infections requiring hospitalisation.
\end{abstract}

Keywords: infections, progressive systemic sclerosis, cyclophosphamide treatment.

\section{Introduction}

Progressive systemic sclerosis (PSS) is one of the most severe systemic diseases of connective tissue. Causal treatment of PSS is yet unknown. Currently used therapies only aim at inhibiting the inflammatory process and progressive multi-organ fibrosis. One of the treatment methods known for years is immunosuppression with cyclophosphamide (CTX). This medicine belongs to standard cytostatic agents used in treatment of autoimmune diseases and cancers. The anti-inflammatory mechanism underlying the effect of CTX metabolites is based on alkylation of deoxyribonucleic acid (DNA) in mature T- and B-cells (and, to a smaller extent, bone marrow precursor cells), resulting in their damage and death $[1,2]$. In PSS cyclophosphamide inhibits progression of interstitial lesions in lungs and has an advantageous influence on skin sclerosis remission [2-4]. It also improves respiratory system efficiency measured as forced vital capacity (FVC) $[3,4,6]$, total lung capacity (TLC) [4] and diffusing capacity of the lungs for carbon monoxide (DLCO) $[7,8]$. Therefore CTX treatment improves quality of patients' life [3]. Recent recommendations of The European League Against Rheumatism (EULAR), published in 2009, recommend considering use of CTX for early lung lesions, scleroderma-related interstitial lung disease (SSC-ILD), as remission-inducing therapy [10]. Despite proven 
efficacy and safety of CTX, this treatment may involve some adverse effects, including infections $[3,10]$. In studies on using CTX in patients with PSS and other autoimmune diseases (vasculitis, systemic lupus erythematosus and others) it was observed that benefits of this therapy exceed a related risk of possible infections [11]. Infection severity depends mainly on the administration route and a cumulative dose of CTX. High-dose intravenous CTX therapy $(50 \mathrm{mg} / \mathrm{kg} / \mathrm{d}$ for 4 consecutive days) not related to a stem cells transplant is mainly applied in treatment of aplastic anaemia [2, 9]. This treatment was also attempted in PSS patients in the past, and it resulted in skin lesions remission and improvement in quality of life [9, 12]. However, this regimen and dosing is associated with a significantly higher number of complications and sometimes required numerous preventive activities, including administration of the granulocyte colony-stimulating factor (G-CSF), mesna, antibiotic therapy, or antifungal treatment. Therefore, currently this regimen is not recommended for PSS treatment. Oral CTX administration at $1-2 \mathrm{mg} / \mathrm{kg} /$ daily results in an even distribution of the dose, usually not requiring prevention of severe infections; however, it is still related to a high cumulative dose, increasing the rate of adverse effects $[3,6]$. However, this dose can be significantly reduced and yet as effective, when CTX is administered intravenously in intravenous pulse therapy at low single doses. Using results of a multicentre, prospective, randomised, double-blind study, it is recommended to replace the oral drug with CTX at a dose of $600 \mathrm{mg} / \mathrm{m}^{2}$, intravenously, once a month for six months [5]. There are numerous examples in the literature confirming effectiveness of low-dose intravenous CTX therapy in PSS patients [11, $13,14,15]$. This treatment regimen may reduce a risk of various adverse effects, including infections, during long-term therapy.

\section{Material and methods}

All 17 women who were included in this study fulfilled the PSS classification criteria of The American College of Rheumatology / The European League Against Rheumatism (ACR/EULAR 2013) [15]. Selected population of patients, received CTX intravenously in a pulse therapy during the mean time of $12.0 \pm 4.0$ months. The mean age in the studied group was $58.8 \pm 10.0$ years (median: 60 years), and the mean disease duration from the moment of its diagnosis was $53.7 \pm 51.1$ months (median: 36 months). The patients were treated with CTX at a dose of $400-800 \mathrm{mg}$, applied as a single dose every 1-3 months. In the studied group, the mean CTX cumulative dose was $9870.6 \mathrm{mg} \pm 6724.2 \mathrm{mg}$ (median: $8600 \mathrm{mg}$ ), ranging from 2000-25600 mg (Table 1).

Table 1. Characteristic of patients with PSS

\begin{tabular}{|c|c|c|c|c|c|c|c|c|c|}
\hline \multirow{2}{*}{$\mathrm{N}$} & \multirow{2}{*}{$\begin{array}{c}\text { Age } \\
\text { (years) }\end{array}$} & \multirow{2}{*}{$\begin{array}{c}\mathrm{DD} \\
\text { (months) }\end{array}$} & \multirow{2}{*}{$\begin{array}{l}\text { CTX } \\
(\mathrm{mg}) \\
\end{array}$} & \multirow{2}{*}{ ANA $^{1}$} & \multicolumn{3}{|c|}{ Immunological profile ${ }^{2}$} & \multirow{2}{*}{$\begin{array}{l}\text { Pulmonary } \\
\text { changes }^{3}\end{array}$} & \multirow{2}{*}{$\mathrm{PAH}$} \\
\hline & & & & & Scl 70 & CENB & $\mathrm{PM}-\mathrm{Scl}$ & & \\
\hline 1. & 64 & 108 & 22800 & positive & +++ & - & - & $(+++)$ & yes \\
\hline 2. & 49 & 84 & 25600 & positive & +++ & - & - & $(+++)$ & yes \\
\hline 3. & 54 & 12 & 4200 & positive & +++ & - & - & negative & - \\
\hline 4. & 65 & 36 & 10800 & positive & +++ & - & - & $(+)$ & - \\
\hline 5. & 61 & 132 & 10000 & positive & - & - & - & $(+++)$ & yes \\
\hline 6. & 57 & 60 & 10200 & positive & + & +++ & - & $(+++)$ & - \\
\hline 7. & 52 & 193 & 5200 & positive & - & - & - & $(++)$ & - \\
\hline 8. & 47 & 24 & 11000 & positive & + & - & - & $(++)$ & yes \\
\hline 9. & 62 & 24 & 7000 & positive & - & - & - & $(+++)$ & yes \\
\hline 10. & 62 & 12 & 6000 & positive & +++ & - & - & $(++)$ & - \\
\hline 11. & 36 & 24 & 9000 & positive & - & + & +++ & $(++)$ & yes \\
\hline 12. & 66 & 12 & 6000 & positive & - & - & - & $(+)$ & - \\
\hline 13. & 60 & 60 & 8600 & positive & - & +++ & - & $(+++)$ & - \\
\hline 14. & 59 & 12 & 4600 & positive & - & - & - & $(+++)$ & - \\
\hline 15. & 76 & 36 & 5000 & positive & + & - & - & $(+++)$ & yes \\
\hline 16. & 54 & 12 & 2000 & - & - & - & - & $(+++)$ & - \\
\hline 17. & 76 & 72 & 19800 & positive & +++ & - & - & $(+++)$ & - \\
\hline
\end{tabular}

1. Detected by the immunoenzymatic test ANA Screen; laboratory standard: $<40 \mathrm{U} / \mathrm{ml}$

2. +- weakly positive result; ++- positive result; +++- strong positive result

3. On a basis of computed tomography; $(+)$ - minimal, preliminary changes, basal fibrosis; $(++)$ - interstitial changes; $(+++)$ - ground-glass opacities, honeycombing

4. Pulmonary arterial hypertension is probable: RVSP $>30 \mathrm{mmHg}$ in the transthoracic echocardiography

$N$ - the number of patients; DD - diseases duration; ANA - antinuclear antibodies; SCl 70 - anti-topomisomerase I antibodies; CENB - anti-centromere protein B antibodies; PM-SCl - anti-polymyositis/scleroderma antibodies; $P A H$ - pulmonary arterial hypertension 
Table 2. Classifications of severity and type of the studied infections in patients with PSS

\begin{tabular}{|c|c|c|}
\hline Type of infection & Treatment of infection & Localization of infection \\
\hline \multirow{3}{*}{ Mild infection } & \multirow{3}{*}{$\begin{array}{l}\text { Infection of mild intensity treated without antibiotics, antiviral } \\
\text { or antifungal medications }\end{array}$} & the upper respiratory tract \\
\hline & & the urinary tract \\
\hline & & skin and/or subcutaneous tissue \\
\hline \multirow{4}{*}{ Moderate infection } & \multirow{4}{*}{$\begin{array}{l}\text { Infection treated with antibiotics, antiviral or antifungal medications } \\
\text { in the ambulatory care, without complications, with rapid regression } \\
\text { of the symptoms }\end{array}$} & the upper respiratory tract \\
\hline & & the lower respiratory tract \\
\hline & & the urinary tract \\
\hline & & skin and/or subcutaneous tissue \\
\hline \multirow{4}{*}{ Severe infection } & \multirow{4}{*}{$\begin{array}{l}\text { Infection requiring hospitalisation, treated by intravenous drugs } \\
\text { or recurrent, chronic, resistant to standard treatment }\end{array}$} & the upper respiratory tract \\
\hline & & the lower respiratory tract \\
\hline & & the urinary tract \\
\hline & & skin and/or subcutaneous tissue \\
\hline
\end{tabular}

Table 3. Infections prevalence rate, type and severity in studied group of patients with Progressive Systemic Sclerosis

\begin{tabular}{ccccccccccccc}
\hline N & \multicolumn{1}{c}{ Mild infection } & \multicolumn{7}{c}{ Moderate infection } & \multicolumn{5}{c}{ Severe infection } \\
\hline & URT & UT & S/SCT & URT & LRT & UT & S/SCT & URT & LRT & UT & S/SCT \\
\hline 1. & - & - & - & - & - & - & - & - & - & - & - \\
\hline 2. & 1 & - & - & 1 & - & - & - & - & - & - & - \\
\hline 3. & - & 1 & - & - & - & 1 & - & - & - & - & - \\
\hline 4. & 2 & - & - & - & - & - & - & - & - & - & - \\
\hline 5. & - & - & - & 1 & - & - & - & - & - & - & - \\
\hline 6. & - & - & - & 3 & - & - & - & - & - & - & - \\
\hline 7. & 5 & 3 & - & - & 2 & - & - & - & 1 & - & - \\
\hline 8. & 2 & - & - & - & - & - & - & - & - & - & - \\
\hline 9. & - & 1 & - & - & - & - & - & - & - & - & - \\
\hline 10. & - & - & - & - & - & - & - & - & - & - & - \\
\hline 11. & 4 & - & - & - & - & - & - & - & - & - & - \\
\hline 12. & 2 & - & - & - & - & - & - & - & - & - & - \\
\hline 13. & - & - & - & - & 1 & - & - & - & - & - & - \\
\hline 14. & - & - & - & 1 & - & - & - & - & - & - & - \\
\hline 15. & 2 & 5 & - & 3 & 1 & 1 & - & - & - & - & - \\
\hline 16. & - & - & - & - & - & - & - & - & - & - & - \\
\hline 17. & - & - & - & - & - & 2 & - & - & - & - & - \\
\hline
\end{tabular}

$N$ - the number of patients; URT - the upper respiratory tract; LRT - the lower respiratory tract; UT - the urinary tract; S/SCT - skin and/or subcutaneous tissue

A retrospective 12-month analysis of infections was conducted in the studied group of PSS patients receiving long-term pulse CTX treatment. The analysis used data collected during interviews, physical examinations, and additional tests, together with all available medical records. For the needs of the study, the infections were divided into three categories: type, treatment options, localization, and also criteria for their classification according to their severity were established (Table 2). In this study the arithmetic mean of infections in each patient was calculated.

\section{Results}

In the studied group of patients with PSS treated with CTX pulse therapy, 46 various infections were found in total during the year analysed retrospectively. The following infection types were found: 28 (60.9\%) mild infections, 17 (37.0\%) moderate infections, and a severe infection in one (2.2\%) patient. Only 4 (23.5\%) had more than 2 infections a year. In each patient, the mean number of infections in the analysed year was $2.7 \pm 3.5$ (median: 2). The majority $(32-69.6 \%)$ of infections concerned the respira- 
tory system, while the remaining 14 (30.4\%) affected the urinary tract. No skin and/or subcutaneous tissue infections were found in the analysed group of patients. Only in one case the infection required hospitalisation and parenteral antibiotic therapy. In three (17.7\%) patients no infection was diagnosed in the period covered by observations.

\section{Discussion}

In the conducted retrospective analysis of the group of PSS patients treated with intravenously administered CTX, the majority of infections were mild and transient. The patients covered by the assessment presented mainly the respiratory system infections, of which over $80 \%$ involved the upper respiratory tract. They were mild and required only a symptomatic treatment. In a population of healthy adults, $2-5$ cases of viral acute rhino-sinusitis, including common cold, were noted per year, and this is comparable to the rate of majority of infections in the studied group [17]. Our analysis showed that patients receiving CTX as a long pulse therapy of single $400-800 \mathrm{mg}$ doses every $1-3$ month do not develop a significant infection frequently, and severity of most of them possibly does not outbalance scientifically proven advantages of this treatment. Basing on the studied group CTX is not a significant factor increasing a risk of severe infections requiring parenteral treatment and/or hospital admission.

CTX therapy inhibits the immune system; therefore, by definition it should increase frequency and severity of infections. Considering the conducted study, it can be established that it is not so, particularly in a case of standard immunosuppressive PSS treatment. In the analysed group of patients, more than half of infections were mild, not requiring causal treatment, and nearly $20 \%$ of patients did not have any infection in the analysed period of time. Only one person suffered a severe infection in form of bronchitis, but it was without complications and resolved with intravenous empiric antibiotic therapy. The conducted analysis was certainly limited by a lack of a relevant control group of PSS patients not receiving immunosuppressive treatment, as well as by inability to obtain details on infection aetiology. Also, it is difficult to compare the results of this study with other reports, as publications on infections in PSS patients chronically treated with CTX are lacking. Nevertheless, the analysis showed that pulse CTX therapy does not increase frequency of severe infections in PSS patients.

\section{Acknowledgements}

\section{Conflict of interest statement}

The authors declare that there is no conflict of interest in the authorship or publication of contribution.

\section{Funding sources}

There are no sources of funding to declare.

\section{References}

1. Manno R, Boin F. Immunotherapy of systemic sclerosis. Immunotherapy. 2010 Nov;2(6):863-878.

2. DeZern AE, Petri M, Drahman DB et al. High dose cyclophosphamide without stem cell rescue in 207 patients with aplastic anemia and other autoimmune diseases.

3. Tashkin DP, Elashoff R, Clements PJ et al. Scleroderma Lung Study Research Group. Cyclophosphamide versus placebo in scleroderma lung disease. $N$ Engl J Med. 2006 Jun 22;354(25):2655-66.

4. Akesson A, Scheja A, Lundin A et al. Improved pulmonary function in systemic sclerosis after treatment with cyclophosphamide. Arthritis Rheum. 1994 May;37(5): 729-35.

5. Hoyles RK, Ellis RW, Wellsbury J et al. A multicenter, prospective, randomized, double-blind, placebo-controlled trial of corticosteroids and intravenous cyclophosphamide followed by oral azathioprine for the treatment of pulmonary fibrosis in scleroderma. Arthritis Rheum. 2006;54:3962-70.

6. Silver RM, Warrick JH, Kinsella MB et al. Cyclophosphamide and low-dose prednisone therapy in patients with systemic sclerosis (scleroderma) with interstitial lung disease. J Rheumatol. 1993 May;20(5):838-44.

7. Davas EM, Peppas C, Maragou M et al. Intravenous cyclophosphamide pulse therapy for the treatment of lung disease associated with scleroderma. Clin Rheumatol. 1999;18(6):455-61.

8. White B, Moore WC, Wigley FM et al. Cyclophosphamide is associated with pulmonary function and survival benefit in patients with scleroderma and alveolitis. Ann Intern Med. 2000 Jun 20;132(12):947-54.

9. Dezern AE, Styler MJ, Drachman DB et al. Repeated treatment with high dose cyclophosphamide for severe autoimmune diseases. Am J. Blood Res. 2013;3(1):84-90.

10. Kowal-Bielecka O, Landewé R, Avouac J et al. EULAR recommendations for the treatment of systemic sclerosis: a report from the EULAR Scleroderma Trials and Research group (EUSTAR). Ann Rheum Dis. 2009 May;68(5):620-8.

11. Haga HJ, D'Cruz D, Asherson R et al. Short term effects of intravenouspulses of cyclophosphamide in the treatment of connective tissue disease crisis. Ann Rheum Dis. 1992 Jul;51(7):885-8.

12. Tehlirian CV, Hummers LK, White B et al. High-dose cyclophosphamide without stem cell rescue in scleroderma. Ann Rheum Dis. 2008 Jun;67(6):775-81.

13. D'Angelo S, Cuomo G, Paone C et al. Low-dose intravenous cyclophosphamide in systemic sclerosis: a preliminary safety study. Clin Rheumatol. 2003 Dec;22(6):393-6.

14. Tochimoto A, Kawaguchi $Y$, Hara $M$ et al. Efficacy and safety of intravenous cyclophosphamide pulse therapy with oral prednisolone in the treatment of intersti- 
tial lung disease with systemic sclerosis: 4-year follow-up. Mod Rheumatol. 2011 Jun;21(3):296-301.

15. Várai G, Earle L, Jimenez SA et al. A pilot study of intermittent intravenous cyclophosphamide for the treatment of systemic sclerosis associated lung disease. J Rheumatol. 1998 Jul;25(7):1325-9.

16. Van den Hoogen F, Khanna D, Fransen J et al. 2013 classification criteria for systemic sclerosis: an American college of rheumatology/European league against rheumatism collaborative initiative. Ann Rheum Dis. 2013 Nov;72(11):1747-55.

17. Fokkens WJ, Lund VJ, Mullol J et al. European Position on Rhinosinusitis and Nasal Polyps 2012. Epidemiology of ARS. Rhinology, 2012; suppl. 23:9-16.
Acceptance for editing: 2015-02-10 Acceptance for publication: 2015-03-30

\section{Correspondence address:} Małgorzata Schlabs Piotr Leszczyński

Department of Rheumatology and Osteoporosis Jozef Strus Hospital 61-285 Poznań, Szwajcarska 3 Secretariat: phone: +48618739260 fax: +48 618739260

email: gosia.schlabs@op.pl, piotr_leszczynski@wp.pl 